\title{
Effect of Cation Structure of Ionic Liquids on Anode Properties of Si Electrodes for LIB
}

\author{
Masahiro Shimizu, ,a,b Hiroyuki Usui, ${ }^{\text {a,b }}$ Kuninobu Matsumoto, ${ }^{\text {a,b }}$ Toshiki Nokami, ${ }^{\text {a,b }}$ \\ Toshiyuki Itoh, ${ }^{\mathrm{a}, \mathrm{b}, *}$ and Hiroki Sakaguchi $\mathbf{i}^{\mathrm{a}, \mathrm{b}, *, \mathrm{z}}$ \\ ${ }^{a}$ Department of Chemistry and Biotechnology, Graduate School of Engineering, Tottori University, Koyama-cho, \\ Tottori 680-8552, Japan \\ ${ }^{b}$ Center for Research on Green Sustainable Chemistry, Tottori University, Koyama-cho, Tottori 680-8552, Japan
}

\begin{abstract}
Ionic liquids consisted of 1-((2-methoxyethoxy)methyl)-1-methylpiperidinium (PP1MEM) or 1-hexyl-1-methylpiperidinium (PP16) and bis(trifluoromethanesulfonyl)amide (TFSA) were applied to an electrolyte for Li-ion battery. The effect of their cation structure on anode properties of Si electrodes were investigated through the use of thick film prepared by gas-deposition without any binder and conductive additive. The Si electrode in PP1MEM-TFSA exhibited an initial reversible capacity of $2670 \mathrm{~mA} \mathrm{~h} \mathrm{~g}^{-1}$, which is larger than that in PP16-TFSA by ca. $900 \mathrm{~mA} \mathrm{~h} \mathrm{~g}^{-1}$. Moreover, a comparatively high capacity of $1150 \mathrm{~mA} \mathrm{~h} \mathrm{~g}^{-1}$ at a high current density of $4200 \mathrm{~mA} \mathrm{~g}^{-1}$ is achieved in PP1MEM-TFSA whereas the Si electrode in PP16-TFSA showed the capacity of only $210 \mathrm{~mA} \mathrm{~h} \mathrm{~g}^{-1}$. Raman analysis and electrochemical impedance measurements revealed that PP1MEM cation played a role reducing the interaction between $\mathrm{Li}$ ion and TFSA anions, and that Li-ion transfer at the electrode-electrolyte interface in PP1MEM-TFSA was remarkably improved compared with PP16-TFSA. These results indicate that the excellent performances obtained in PP1MEM-TFSA originate from a smooth $\mathrm{Li}$-insertion into $\mathrm{Si}$ electrode. It was suggested that introduction of ether functional group into cation is valid to enhance the electrode performance.

(C) 2014 The Electrochemical Society. [DOI: 10.1149/2.0021412jes] All rights reserved.
\end{abstract}

Manuscript submitted May 12, 2014; revised manuscript received July 25, 2014. Published August 8, 2014.

Li-ion battery (LIB) has been utilized in large-scale battery systems such as power supply of electric vehicles in recent years. Unfortunately, the conventional LIB using graphite anode has insufficient energy density to satisfy the growing demand. Silicon is one of promising candidates of anode materials for next-generation LIB due to its huge theoretical capacity compared with that of graphite practically used. Si and Li form several Li-rich binary alloy phases such as $\mathrm{Li}_{15} \mathrm{Si}_{4}$ at room temperature and $\mathrm{Li}_{22} \mathrm{Si}_{5}$ at a high temperature of $415^{\circ} \mathrm{C}$, which offers extremely high theoretical capacities of 3580 and $4200 \mathrm{~mA} \mathrm{~h} \mathrm{~g}^{-1}$, respectively. ${ }^{1-3}$ The volume of $\mathrm{Si}$ is, however, significantly changed during alloying/dealloying reactions. The volumetric change ratios per $\mathrm{Si}$ atom from $\mathrm{Si}$ to $\mathrm{Li}_{15} \mathrm{Si}_{4}$ and $\mathrm{Li}_{22} \mathrm{Si}_{5}$ correspond to $380 \%$ and $410 \%$, which results in a generation of high stress and large strain in the active material. The strain accumulated by repeating charge-discharge cycle causes a disintegration of Si electrodes, leading to a rapid capacity fading and a poor cycle stability. In addition, $\mathrm{Si}$ has disadvantages of a low electrical conductivity and a low diffusion coefficient of $\mathrm{Li}^{+}$in it $\left(D_{\mathrm{Li}+}, 10^{-14}\right.$ to $\left.10^{-12} \mathrm{~cm}^{2} \mathrm{~s}^{-1}\right){ }^{4-6}$ For these reasons, a practical application of $\mathrm{Si}$ electrodes has been hindered. To overcome these problems, considerable attempts have been carried out. Many researchers have studied composite materials consisted of carbon, with mechanically soft property and good electrical conductivity, and pure $\mathrm{Si}^{7-10} \mathrm{We}$ have recently demonstrated that composite electrodes prepared by using $\mathrm{LaSi}_{2} / \mathrm{Si}$ and $\mathrm{Ni}-\mathrm{P} / \mathrm{Si}$ exhibit a high anode performance because $\mathrm{LaSi}_{2}$ and $\mathrm{Ni}-\mathrm{P}$ effectively compensate for silicon's disadvantages. ${ }^{11-14}$

Meanwhile, an electrolyte is also one of the most important factors that determines the battery performance. Room temperature ionic liquids have received intensive attentions as an alternative to conventional organic electrolytes based on carbonate solvents because of their excellent physicochemical properties of high thermal stability, negligible vapor pressure, wide electrochemical window, and high ionic conductivity. ${ }^{15-18}$ Nevertheless, there have been a few reports on Si-based electrode in ionic liquid electrolytes. ${ }^{19-24} \mathrm{Kim}$ et al. prepared $\mathrm{FeSi}_{2.7}$ thin-film by using a $\mathrm{RF}$ magnetron sputtering, and investigated its electrochemical behaviors in $N$-buthyl- $N$-methylpyrrolidinium bis(trifluoromethanesulfonyl)amide (Py14-TFSA). Although the electrode showed a lower reversible capacity of $760 \mathrm{~mA} \mathrm{~h}$ $\mathrm{g}^{-1}$ than that obtained from an organic electrolyte at the first cycle, an excellent capacity retention of $92 \%$ at the 100th cycle was achieved

\footnotetext{
*Electrochemical Society Active Member.
}

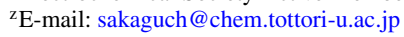

in the ionic liquid electrolyte. The reason for the lower initial capacity was suggested to be increase in two kinds of resistance: Li-ion migration in ionic liquid and charge transfer reaction on the electrode. ${ }^{25}$ We also demonstrated that the cycle stability of Si-based electrodes are remarkably improved by applying commercial ionic liquids to an electrolyte. ${ }^{26-28}$ In the case of using ionic liquid electrolytes, however, charge-discharge ( $\mathrm{Li}$ insertion-extraction) capacities of Si electrode are tend to be smaller than that in organic electrolytes due to the slower kinetics of Li-ion transfer at the interface between the electrode and the electrolyte. In the TFSA-based ionic liquid electrolytes, $\mathrm{Li}$ ion is four-coordinated through the oxygen atoms of two bidentate TFSA anions to form $\left[\operatorname{Li}(\mathrm{TFSA})_{2}\right]^{-}$ion clusters. ${ }^{29-31}$ In addition to this, ionic liquids do not contain any neutral molecules. Therefore, when an electrode is negatively charged, the cations of ionic liquids are accumulated on the electrode surface to compensate the negative charge of the electrode, and the solvated Li-ions ([Li(TFSA $\left.)_{2}\right]^{-}$) exist opposite to the cations in Helmholtz layer, which forms electric double layer at the electrode-electrolyte interface. ${ }^{32,33} \mathrm{Li}$-insertion reaction into Si proceeds via several steps: (1) Li-ion migration in the electrolyte bulk, (2) desolvation of [Li(TFSA $\left.)_{2}\right]^{-}$and Li-ion transport in the electric double layer and/or a solid electrolyte interphase (SEI) layer, (3) alloying reaction of $\mathrm{Si}$ with $\mathrm{Li}$, (4) $\mathrm{Li}$ diffusion in $\mathrm{Si}^{34}$ Among these components, desolvation process is hard to occur by strongly electrostatic interaction between Li ion and TFSA anions, which impedes Li-insertion into Si compared with organic electrolyte system. ${ }^{25}$ Charge-discharge capacities are thus limited in the ionic liquid electrolytes system. We consider that if cation of ionic liquid has functionality reducing the interaction between Li ion and TFSA anions, it can enable efficient Li-ion transfer at the electrode-electrolyte interface. As a result, Li-insertion reaction can easily occur, and it can provide the enhancement of charge-discharge capacities of Si electrode. Jung et al. investigated anode properties of graphite electrodes in TFSA-based ionic liquid electrolytes consisted of pyrrolidinium cation with various functional groups by using cyclic voltammetry, and reported that the Li insertion-extraction properties are involved with cation structure of ionic liquids. ${ }^{35}$ There has been, however, no study that tried to improve the anode performance of Si electrodes by modifying the cation structure of ionic liquid to the authors' knowledge.

We recently revealed that excellent cycle performanes of Si-based electrodes were achieved in the ionic liquid consisted of piperidinium cation and TFSA anion, and that the electrode performances originate from its high stability against cathodic decomposition. ${ }^{26-28}$ TFSA-based ionic liquids show a much higher thermal stability than 


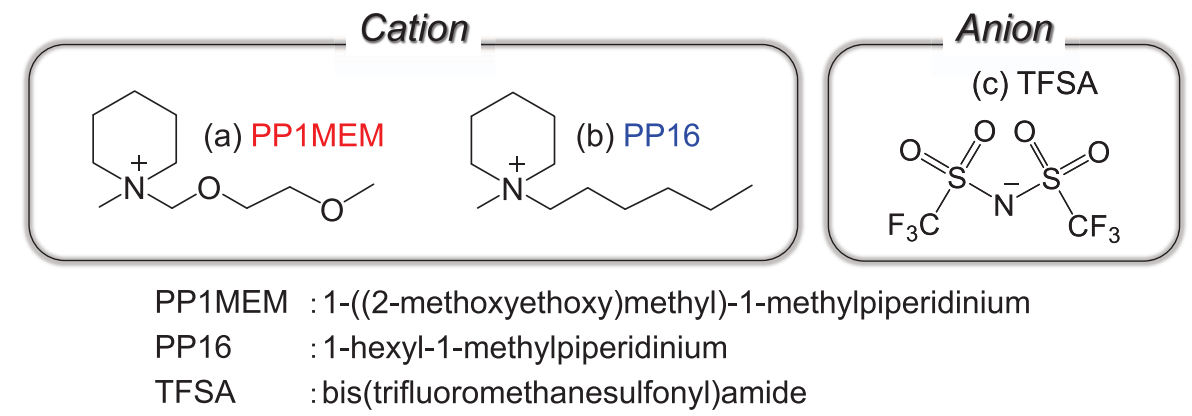

Figure 1. Cation and anion structures of ionic liquids used in this study. (a) 1-((2methoxyethoxy)methyl)-1-methylpiperidinium. (b) 1-hexyl-1-methylpiperidinium. that obtained from ionic liquids with bis(fluorosulfonyl)amide (FSA) anion, which has a strong advantage in the light of insuring safety of battery. ${ }^{36}$ In this study, therefore, we introduced ether group having electron-donating ability into piperidinium cation to reduce the electrostatic interaction between Li ion and TFSA anions by its oxygen atom of local negative charge. For comparison, we also synthesized ionic liquid with alkyl-substituted piperidinium cation having as same chain length as ether-substituted one. In order to directly observe the electrochemical reaction between $\mathrm{Si}$ electrode and the electrolyte, $\mathrm{Si}$ thick-films prepared by a gas-deposition (GD) method were used. This method does not require any binder and conductive additive to prepare thick-film electrodes. ${ }^{37,38}$ It enables us to clarify an original anode property of pure Si electrode. We herein report the effect of cation structure of ionic liquids on anode properties of Si electrodes from the viewpoint of the interaction between Li ion and TFSA anions.

\section{Experimental}

Characterization of ionic liquids. - Two kind of ionic liquids were synthesized by organic method as previously reported. ${ }^{39}$ Figure 1 shows cation and anion structures of ionic liquids used in this study. One is 1-((2-methoxyethoxy)methyl)-1-methylpiperidinium bis(trifluoromethanesulfonyl)amide (PP1MEM-TFSA). The other is 1-hexyl-1-methylpiperidinium bis(trifluoromethanesulfonyl)amide (PP16-TFSA). All ionic liquids were dried under vacuum at $100^{\circ} \mathrm{C}$ for $10 \mathrm{~h}$ to remove water before analysis described below, and we confirmed water content less than 50 ppm by a Karl-Fisher moisture titrator (Labconco Corporation, FZ-Compact). The viscosity of the ionic liquids was measured by using an E-type viscometer (Visconic ED, TOKYO KEIKI Inc.) under air atmosphere at $303 \mathrm{~K}$. The electrical conductivity was investigated by an electrochemical impedance measurement (CompactStat, Ivium Technologies) through the use of the cell equipped with two Pt electrodes under argon atmosphere at various temperatures from 293 to $353 \mathrm{~K}$. A thermogravimetric (TG) analysis was conducted to determine thermal decomposition temperature of ionic liquids by using a TG analyzer (Thermo plus EVO II, Rigaku Co., Ltd.) with a heating rate of $10^{\circ} \mathrm{C} \mathrm{m^{-1 }}$ from ambient temperature to $500^{\circ} \mathrm{C}$ under argon atmosphere.

Preparation of Si thick-film electrodes.- Si thick-film electrodes were prepared by a gas-deposition method using commercial Si powder (Wako Pure Chemical Industries, Ltd. 99.9\%). ${ }^{26-28}$ For gasdeposition, a current collector of $\mathrm{Cu}$ foil substrate with $20 \mu \mathrm{m}$ in thickness was set at a distance of $10 \mathrm{~mm}$ from nozzle in a vacuum chamber with a guide tube. The nozzle with $0.8 \mathrm{~mm}$ in diameter was connected at the end of guide tube. An argon carrier gas with a purity of $99.99 \%$ was set under a differential pressure of $7.0 \times 10^{5} \mathrm{~Pa}$. After the chamber was evacuated to a base pressure of several ten $\mathrm{Pa}$, an aerosol consisting of the carrier gas and the active material powder was generated in the guide tube, and instantly gushed from the nozzle to the $\mathrm{Cu}$ substrate. The weight of the deposited active material on the substrate was measured to an accuracy of $1 \mu \mathrm{g}$ by ultra-microbalance (XP6, METTLER TOLEDO) equipped with anti-vibration table, and we used Si thick-film electrode in the range of $28-30 \mu \mathrm{g}$. Observation by a confocal laser scanning microscope (CSLM, VK-9700, Keyence) revealed that the thickness of Si film is ca. $2 \mu \mathrm{m}$.
Evaluation for anode properties of Si electrodes in ionic liquid electrolytes. - We fabricated 2032-type coin cells consisted of Si thick-film electrode as working electrode, Li foil (Rare Metallic, $99.90 \%$, thickness: $1.0 \mathrm{~mm}$ ) as counter electrode, ionic liquid electrolyte, and propylene-based separator. The areas of the Si thickfilm and $\mathrm{Li}$ sheet in the cell are $0.5 \mathrm{~cm}^{2}$ and $1.90 \mathrm{~cm}^{2}$, respectively. The electrolytes were prepared by dissolving a salt of lithium bis(trifluoromethanesulfonyl)amide (LiTFSA) in each piperidiniumbased ionic liquid with a concentration $1.0 \mathrm{~mol} \mathrm{~L}^{-1}(\mathrm{M})$. For comparison, we used an organic-based electrolyte of 1.0 M LiTFSA-dissolved in propylene carbonate ( $\mathrm{PC} ; \mathrm{C}_{4} \mathrm{H}_{6} \mathrm{O}_{3}$, Kishida Chemical Co., Ltd.). The preparation of the electrolytes and the cell assembly were performed throughout in a purge-type glove box (Miwa MFG, DBO2.5LNKP-TS) filled with argon atmosphere in which oxygen and water were completely removed. The glove box maintained a dew point below $-100^{\circ} \mathrm{C}$ and oxygen content below $1 \mathrm{ppm}$. Charge-discharge tests were carried out using an electrochemical measurement system (HJ-1001 SM8A, Hokuto Denko Co., Ltd.) in the potential range between 0.005 and $2.000 \mathrm{~V}$ vs. $\mathrm{Li} / \mathrm{Li}^{+}$at $303 \mathrm{~K}$ under the constant current density of $0.42 \mathrm{~A} \mathrm{~g}^{-1}(0.12 \mathrm{C})$. An electrochemical impedance spectroscopic (EIS) analysis was performed at $0.005 \mathrm{~V} \mathrm{vs.} \mathrm{Li}^{\prime} / \mathrm{Li}^{+}$in the frequency of $100 \mathrm{kHz}$ to $10 \mathrm{mHz}$ with amplitude of $5 \mathrm{mV}$. The surface morphologies of the Si thick-film electrodes after charge-discharge cycle were observed by a field-emission scanning electron microscope (FE-SEM, JSM-6701F JEOL Co., Ltd.). An analysis of the interactions between $\mathrm{Li}$ ion and TFSA anions in each ionic liquid electrolyte were conducted by a Raman microscopy system (NanofinderFLEX, Tokyo Instruments, Inc.) with $532 \mathrm{~nm}$ line of Nd:YAG laser at room temperature.

\section{Results and Discussion}

The physicochemical properties of piperidinium-based ionic liquids synthesized in this study are summarized in Table I. PP1MEMTFSA exhibited approximately half viscosity compared with that of PP16-TFSA, which means that a coulombic interaction between the dissociated cation and anion was weakened by its ether functional group in PP1MEM cation. It is well known that introducing of alkoxy group having electron-donating ability into quaternary ammonium cation reduces viscosity of ionic liquids. ${ }^{40-42}$ Consequently,

Table I. Summary of physicochemical properties of TFSA-based ionic liquids synthesized in this study. The electrolytes were prepared by dissolving of LiTFSA with a concentration of $1.0 \mathrm{M}$.

\begin{tabular}{cccccc} 
Cation & M.W. $^{\mathrm{a}}$ & $\eta^{\mathrm{b}} / \mathrm{mPa} \mathrm{s}$ & $\begin{array}{c}\sigma^{\mathrm{c}} / \mathrm{mS} \mathrm{cm}^{-1} \\
\text { (neat) }\end{array}$ & $\begin{array}{c}\sigma^{\mathrm{c}} / \mathrm{mS} \mathrm{cm}^{-1} \\
(\mathrm{electrolyte})\end{array}$ & $T_{\mathrm{dec}}{ }^{\mathrm{d} /{ }^{\circ} \mathrm{C}}$ \\
\hline PP1MEM & 468 & 69 & 2.3 & 0.7 & 285 \\
PP16 & 464 & 132 & 0.8 & 0.4 & 415
\end{tabular}

${ }^{\mathrm{a}}$ Molecular weight.

${ }^{\mathrm{b}}$ Viscosity at $303 \mathrm{~K}$.

${ }^{\mathrm{c}}$ Conductivity at $303 \mathrm{~K}$.

${ }^{\mathrm{d}}$ Thermal decomposition temperature (10\% weight loss). 


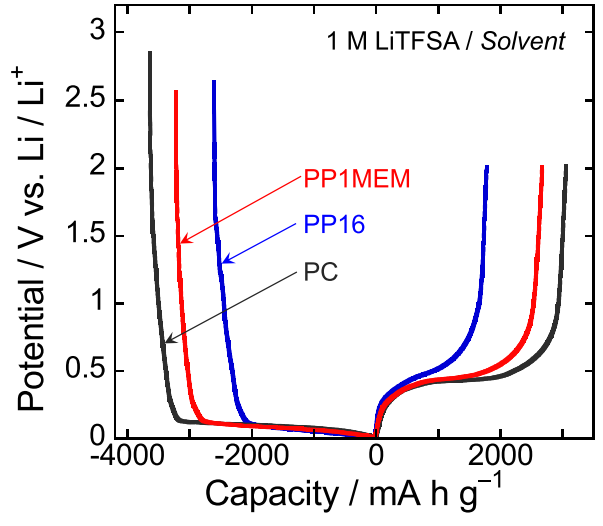

Figure 2. Initial charge-discharge curves of Si thick-film electrodes in ionic liquid electrolytes with cations of PP1MEM and PP16, and in organic-based electrolyte of PC.

in PP1MEM-TFSA system, the higher conductivities were obtained from not only neat ionic liquid but also the electrolyte. The two kind of ionic liquids showed no decomposition at least up to $250^{\circ} \mathrm{C}$, though the weight loss of PP1MEM-TFSA was detected at a lower temperature in comparison with PP16-TFSA. The high thermal stability of these ionic liquids is superior to organic solvents, which can enhance the safety of LIB.

Figure 2 shows the first charge-discharge (Li insertionextraction) curves of Si thick-film electrodes in the piperidiniumbased ionic liquid electrolytes and organic electrolyte using PC. In every case, potential plateaus were observed at around 0.1 and 0.4 $\mathrm{V}$ vs. $\mathrm{Li} / \mathrm{Li}^{+}$on charge-discharge curves, indicating alloying and dealloying reactions of $\mathrm{Si}$ with $\mathrm{Li}$. In PC, the initial charge and discharge capacities were 3640 and $3060 \mathrm{~mA} \mathrm{~h} \mathrm{~g}^{-1}$, respectively, with the first coulombic efficiency of $84 \%$. The irreversible capacity is attributed to a formation of surface layer induced by a reductive decomposition of electrolyte, and the surface layer is mainly consisted of organic and inorganic compounds such as lithium alkyl carbonates $\left(\mathrm{ROCO}{ }_{2} \mathrm{Li}\right)$ and lithium carbonate $\left(\mathrm{Li}_{2} \mathrm{CO}_{3}\right) .{ }^{43}$ By contrast, Si electrode in PP16-TFSA showed the relatively small discharge capacity of $1780 \mathrm{~mA} \mathrm{~h} \mathrm{~g}^{-1}$. The initial charge capacity based on $\mathrm{Li}-\mathrm{Si}$ alloying reaction can be estimated to be about $2070 \mathrm{~mA} \mathrm{~h} \mathrm{~g}^{-1}$ from range of $\mathrm{Li}$-insertion plateau between 0.005 and $0.120 \mathrm{~V}$ vs. $\mathrm{Li}^{2} / \mathrm{Li}^{+}$. This capacity corresponds to $58 \%$ of the silicon's theoretical capacity $(3580$ $\mathrm{mA} \mathrm{h} \mathrm{g}^{-1}$ ). It is consider that the low utilization of $\mathrm{Si}$ is caused by slow kinetics of Li-ion transfer at the interface between the electrode and the electrolyte. ${ }^{25,27}$ In the TFSA-based ionic liquid electrolytes, Li-ion is four-coordinated through the oxygen atoms of two bidentate TFSA anions. ${ }^{29-31}$ The strongly electrostatic interaction between $\mathrm{Li}$ ion and TFSA anions impedes $\mathrm{Li}$-insertion reaction into $\mathrm{Si}$, which causes the decrease in discharge capacity as well as charge capacity as in the PP16-TFSA. It was noteworthy that the discharge capacity of $2670 \mathrm{~mA} \mathrm{~h} \mathrm{~g}^{-1}$ was achieved in PP1MEM-TFSA. An important point to be emphasized is that the capacity was much higher than that in PP16-TFSA by ca. $900 \mathrm{~mA} \mathrm{~h} \mathrm{~g}^{-1}$ though these ionic liquids consist of the same anion of TFSA. To evaluate reproducibility, the performances were measured for another electrodes. The standard deviations in the first discharge capacities for PC, PP1MEM-TFSA, and PP16TFSA are $3058 \pm 0.850 \mathrm{~mA} \mathrm{~h} \mathrm{~g}^{-1}, 2681 \pm 7.95 \mathrm{~mA} \mathrm{~h} \mathrm{~g}^{-1}$, and 1887 $\pm 106 \mathrm{~mA} \mathrm{~h} \mathrm{~g}^{-1}$, respectively. Although the standard deviation in PP16-TFSA is larger than that in PP1MEM-TFSA, a superiority of PP1MEM-TFSA is evident. This result indicates that introducing of ether functional group into cation is valid to exert the high theoretical capacity of Si. We thought that the initial large capacity in PP1MEMTFSA was presumably due to a smooth Li-ion transfer at interface between the electrode and the electrolyte.

In order to investigate electrochemical behaviors of $\mathrm{Li}$-ion at the interface, an electrochemical impedance measurements were conducted in the frequency range of $100 \mathrm{kHz}$ to $10 \mathrm{mHz}$. Figure 3 displays Nyquist plots of Si thick-film electrode charged at $0.005 \mathrm{~V}$ vs. $\mathrm{Li} / \mathrm{Li}^{+}$ in each electrolyte. In all of the Nyquist plots, it was observed two semicircles and a straight line with a slope of approximately $45^{\circ}$ in high frequency region and low frequency region, respectively. The first semicircle denotes interfacial resistance $\left(R_{\mathrm{if}}\right)$, and is associated with interfacial Li-ion transfer processes that includes desolvation of $\left[\mathrm{Li}(\mathrm{TFSA})_{2}\right]^{-}, \mathrm{Li}$-ion transport in electrical double layer and/or a surface layer induced by the decomposition of electrolyte. ${ }^{24}$ The second semicircle corresponds charge transfer resistance $\left(R_{\mathrm{ct}}\right)$, and is related to the process of $\mathrm{Li}-\mathrm{Si}$ alloying reaction. ${ }^{34}$ The straight line in the low frequency named as Warburg impedance $\left(Z_{\mathrm{w}}\right)$ is derived from solidstate diffusion of $\mathrm{Li}$ in $\mathrm{Si}^{28}$ Resistances of these components were analyzed by using an equivalent circuit shown in Figure $3 \mathrm{a}$. We do not discuss here a component of surface layer because it is still a debatable point. The interfacial resistances $\left(R_{\mathrm{if}}\right)$ in PP1MEM-TFSA and PP16TFSA were $90 \Omega \mathrm{cm}^{2}$ and $230 \Omega \mathrm{cm}^{2}$, respectively, and respective charge transfer resistances $\left(R_{\mathrm{ct}}\right)$ were $130 \Omega \mathrm{cm}^{2}$ and $200 \Omega \mathrm{cm}^{2}$. Both the resistance values in PP1MEM-TFSA were lower than those obtained in PP16-TFSA as expected. In particular, interfacial resistance in PP1MEM-TFSA was less than half of that in PP16-TFSA, indicating a smooth Li-ion transfer at the electrode-electolyte interface. It
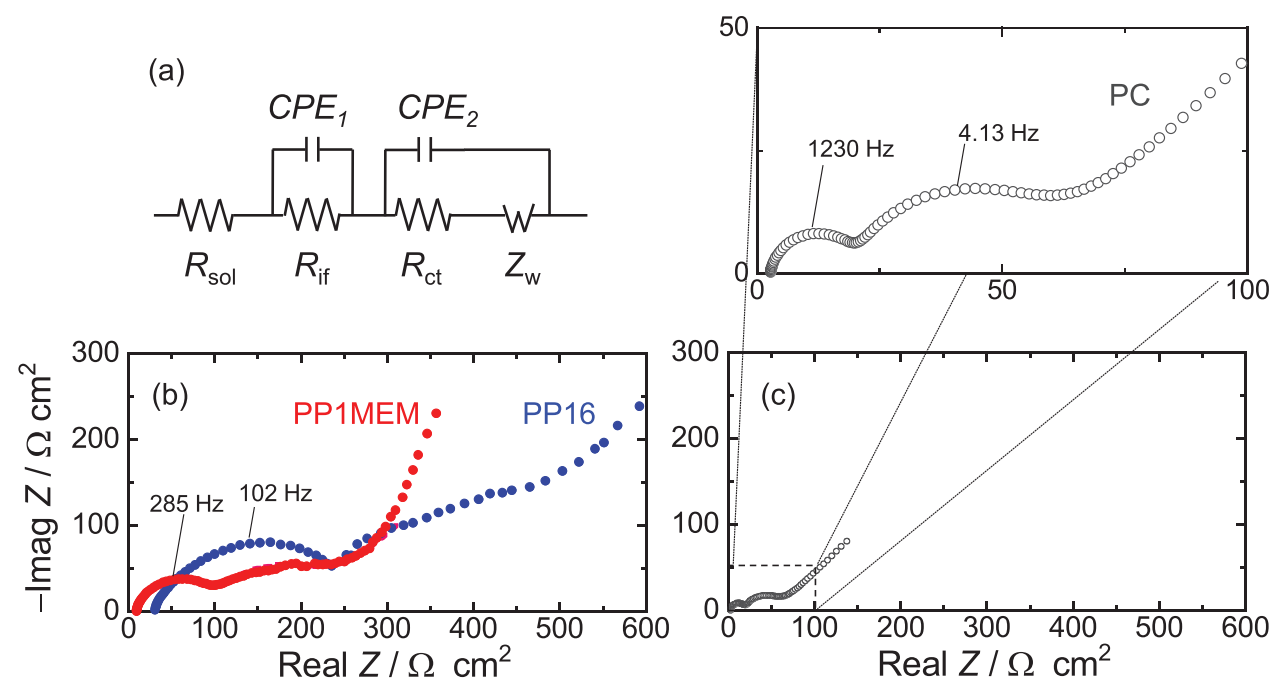

Figure 3. (a) Equivalent circuits for impedance analysis in this study. Nyquist plots of Si thick-film electrodes charged at 0.005 V in (b) PP1MEM-TFSA and PP16-TFSA. For comparison, the Nyquist plots in (c) PC was also plotted. 


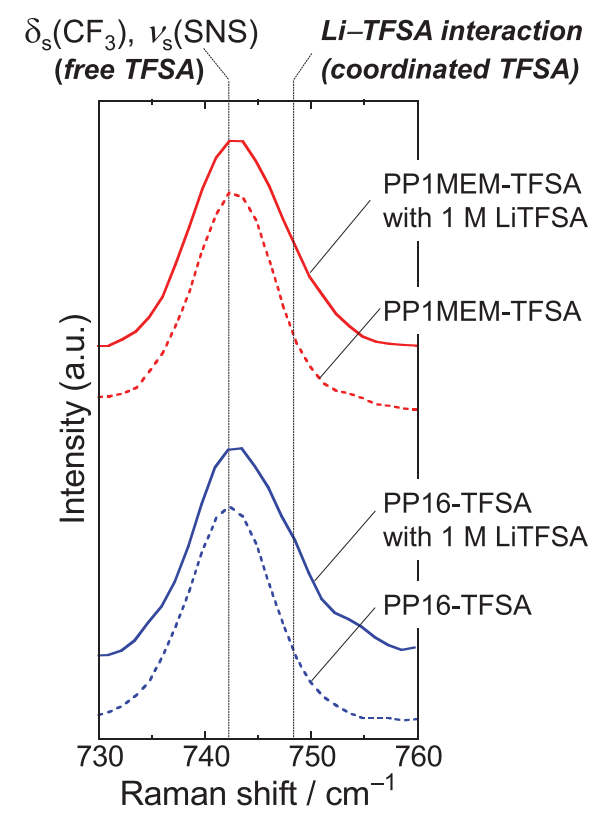

Figure 4. Raman spectra of ionic liquids and the electrolytes consisted of the piperidinium-based ionic liquids and LiTFSA in the frequency range of 730 to $760 \mathrm{~cm}^{-1}$. The cations of ionic liquids are PP1MEM (upper) and PP16 (lower), respectively.

was speculated that the charge transfer resistance in PP1MEM-TFSA reduced as a result of improving the $\mathrm{Li}$-insertion into the $\mathrm{Si}$ electrode. In the case of using PC, the interfacial resistance and charge transfer resistance became the smallest value among the three kind of electrolytes. These lower resistances originate from weaker interaction between $\mathrm{Li}$ ion and solvent molecules in organic electrolyte compared with the electrostatic interaction between Li ion and TFSA anions in ionic liquid electrolyte system. The magnitude of charge and discharge capacities in each electrolyte depends on the values of the respective interfacial resistances. From the results of EIS measurements, we thought that the smooth Li-ion transfer in PP1MEM-TFSA is owing to the reduced interaction between Li-ions and TFSA anions in comparison with PP16-TFSA.

To investigate the interactions between Li ion and TFSA anions in each ionic liquid electrolyte, Raman spectroscopic measurements were carried out. Figure 4 compares Raman spectra for the neat ionic liquids and the electrolytes containing LiTFSA with a concentration of $1.0 \mathrm{M}$ in the frequency range of 730 to $760 \mathrm{~cm}^{-1}$. The intense bands were observed at $742 \mathrm{~cm}^{-1}$ in all cases, which is ascribed to the $\mathrm{CF}_{3}$ bending vibration $\delta_{\mathrm{s}}\left(\mathrm{CF}_{3}\right)$ coupled with the $\mathrm{S}-\mathrm{N}$ stretching vibration $\nu_{\mathrm{s}}(\mathrm{S}-\mathrm{N}-\mathrm{S})$ of the TFSA anion. ${ }^{44-46}$ This band is assigned to "free" TFSA anions, where Li ion is not coordinated by TFSA anions. In other words, it means the interaction between dissociated cation and TFSA anion in ionic liquid. On the other hand, it is well known that the band position of $742 \mathrm{~cm}^{-1}$ showing the interaction shifts to $748 \mathrm{~cm}^{-1}$ by coordination of TFSA anions to $\mathrm{Li}$ ion. ${ }^{29,31,47}$ For electrolytes containing LiTFSA, we can confirm shoulders at around $748 \mathrm{~cm}^{-1}$ in the Raman spectrum of each ionic liquid electrolyte. In addition, the shoulder in the PP1MEM-TFSA was obviously smaller than that observed in PP16-TFSA, which suggests that the interaction between Li ion and TFSA anions in PP1MEM-TFSA is less than that in PP16-TFSA. In order to exactly explore the interactions in each electrolyte, their Raman spectra were separated into the two components including uncoordinated TFSA anions (free TFSA) and coordinated TFSA anions (Li-TFSA) by deconvolution processing as shown in Figure 5. Comparing the intensity ratios of coordinated TFSA that interacts with $\mathrm{Li}$ ions, the relative ratio of Li-TFSA interaction in PP1MEM-TFSA system was smaller than that PP16-TFSA system. Kunze et al. have studied an interaction (a) 1 M LiTFSA / PP1MEM-TFSA

(b) 1 M LiTFSA / PP16-TFSA

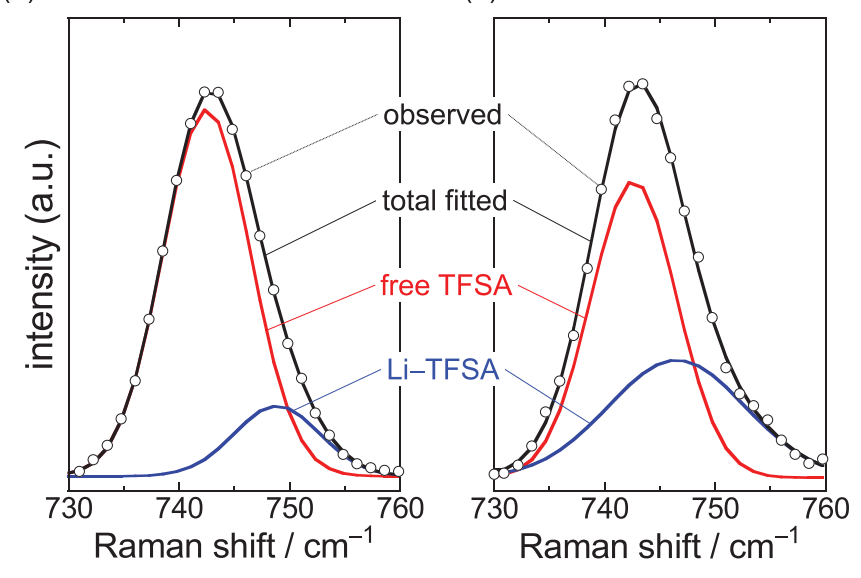

Figure 5. Decomvoluted Raman bands of 1.0 M LiTFSA-dissolved in (a) PP1MEM-TFSA and (b) PP16-TFSA. The dotted, black, blue, and red lines show the observed spectrum, the total Raman spectrum, the deconvoluted components of free TFSA anion and coordinated TFSA anion (Li-TFSA).

in mixture of LiTFSA and pyrrolidinium-based ionic liquid with cation having alkyl side chain or ether side chain by Raman spectroscopic measurement and nuclear magnetic resonance analysis. ${ }^{48}$ According to this literature, less than two anions are required for the coordination of $\mathrm{Li}$ ion in 1-(ethoxymethyl)-1-methylpyrrolidinium bis(trifluoromethanesulfonyl)amide (Pyr1[201]-TFSA) whereas more than two TFSA anions are necessary to solvate Li ion in the 1-butyl-1-methylpyrrolidinium bis(trifluoromethanesulfonyl)amide (Pyr14-TFSA). The coordination number of TFSA anions to Li ion are 1.55 and 2.12, respectively. This result indicates that the Li-TSFA interaction can be weaken by introducing of ether functional group into cation of ionic liquid, and agrees with our results of Raman measurements. The intensity ratios of Li-TFSA to uncoordinated TFSA (free TFSA) in PP1MEM-TFSA and PP16-TFSA are 0.19 and 0.34 , respectively, which suggests that the coordination number of TFSA anions to Li ion in PP1MEM-TFSA is less than two, and smaller than that in PP16-TFSA. Although the total charge of PP1MEM cation is +1.0 , the oxygen atoms in the cation are negatively charged due to its electron-withdrawing nature. We therefore consider the effect reducing the interaction between Li ion and TFSA anions by PP1MEM cation originates from the two oxygen atoms in the cation structure. Possible reasons for the small coordination number in PP1MEM-TFSA are one or more of the following: (i) a repulsive force due to electrostatic interaction between TFSA anion and local negative charge of oxygen atoms in the PP1MEM cation, (ii) an attractive force due to electrostatic interaction between an isolated $\mathrm{Li}$ ion and the oxygen atoms, (iii) an attractive electrostatic interaction between $\mathrm{Li}$ ion binding with TFSA anion and the oxygen atoms. However, it is thought that $\mathrm{Li}$ ion in TFSA-based ionic liquid electrolytes is preferentially solvated by TFSA anions owing to a very strong interaction between $\mathrm{Li}$ ion and TFSA anion. ${ }^{49}$ In addition, the results of Raman measurements for the ionic liquid electrolytes shows the fact that the interaction between $\mathrm{Li}$ ion and the oxygen atoms of PP1MEM cation coexists with the interaction between $\mathrm{Li}$ ion and TFSA anion, which is probably in a competitive relationship. Tsuzuki et al. have studied the an interaction of LiTFSA complex with $N, N$-diethyl- $N$-methyl- $N$-2-methoxyethylammonium (DEME) cation and DEME-TFSA by ab initio molecular calculations. ${ }^{50}$ Interaction energy potentials $\left(E_{\text {int }}\right)$ calculated for DEME-Li systems in various geometries are always repulsive though the potential has a local minimum when the $\mathrm{Li}$ ion approaches the oxygen atom in DEME cation with a distance of $2.0 \AA$, which shows that an isolated $\mathrm{Li}$ ion does not form the stable complex with DEME cation. Meanwhile, the potential calculated for DEME-LiTFSA complex has a minimum in a similar way to the DEME-Li system when the $\mathrm{Li} \cdots \mathrm{O}$ distance 


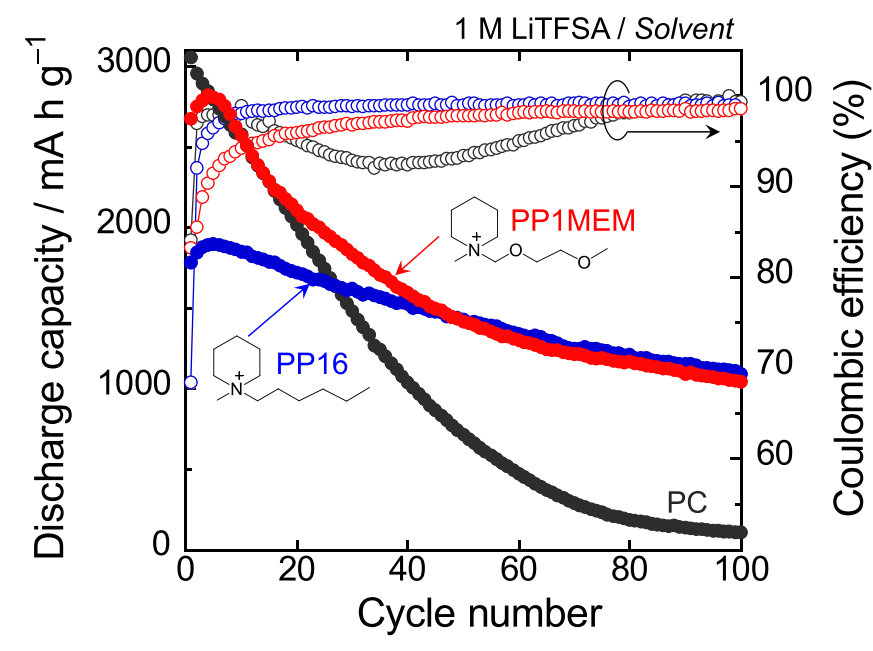

Figure 6. Dependence of discharge (Li-extraction) capacities and coulombic efficiencies on cycle numbers for Si electrodes in PP1MEM-TFSA and PP16TFSA. For comparison, the performance in PC was also plotted.

is $2.0 \AA$. $E_{\text {int }}$ of fully optimized geometry of the DEME-LiTFSA complex at the HF/6-311G** level is $-18.4 \mathrm{kcal} \mathrm{mol}^{-1}$. Furthermore, they calculated an interaction between DEME-TFSA and LiTFSA complex in view of a bulk ionic liquid environment, and reported that its $E_{\text {int }}\left(-23.2 \mathrm{kcal} \mathrm{mol}^{-1}\right)$ for most stable orientation is substantially larger than that for the DEME-LiTFSA complex. Based on the results of ab initio calculations, we consider the effects of the PP1MEM cation on the coordination number of TFSA anion to $\mathrm{Li}$ ion as follows. PP1MEM cation in the electrolyte attracts $\mathrm{Li}$ ion interacting TFSA anion through the two oxygen atoms in the cation structure by an electrostatic interaction between the positively charged $\mathrm{Li}$ ion and the negatively charged oxygen atoms. After that, a complex consisted of PP1MEM cation and LiTFSA is formed, and the complex is surrounded by an additional TFSA anion for a charge compensation. On the other hand, alkyl group of PP16 cation has no electron-withdrawing nature, and thereby permit at least more than two TFSA anions to coordinate $\mathrm{Li}$ ion. This appears to be a reason why the coordination number of TFSA anions to $\mathrm{Li}$ ion in PP1MEM-TFSA is smaller than that in PP16-TFSA. When an negative electrode is charged to provide capacity, the cations of ionic liquids are accumulated on the electrode surface, and the $\left[\operatorname{Li}(\text { TFSA })_{x}\right]^{1-x}$ exists opposite the cations in Helmholtz layer. The symbol " $x$ " denotes coordination number, and generally results in " 2 ", Desolvation of $\left[\operatorname{Li}(\operatorname{TFSA})_{x}\right]^{1-x}$ occurs at the electrode-electrolyte interface before Li-insertion into $\mathrm{Si}$. The desolvation process is impeded by strongly electrostatic interaction between $\mathrm{Li}$ ion and TFSA anions in comparison with organic electrolytes system, which limits charge-discharge capacities in the ionic liquid electrolytes system. In consequence, the capacities become smaller with increasing coordination number due to its slow kinetics, as observed in PP16-TFSA. It was revealed that PP1MEM cation played a role reducing the interaction between $\mathrm{Li}$ ion and TFSA anions, and the coordination number was less than two. The decrease in the number led to significant increase in capacities of Si electrode. It was demonstrated that PP1MEM cation enhanced not only Li-ion transfer at the electrode-electrolyte interface but also the initial charge-discharge capacities of Si electrode.

Figure 6 represents a dependence of discharge (Li-extraction) capacities and coulombic efficiencies on cycle numbers for Si electrodes in the piperidinium-based ionic liquid electrolytes. For comparison, the performance in $\mathrm{PC}$ was also plotted in this figure. Although $\mathrm{Si}$ electrode in PC showed the high discharge capacity of $3060 \mathrm{~mA} \mathrm{~h}$ $\mathrm{g}^{-1}$ at the first cycle, the capacity was quickly decreased to $110 \mathrm{~mA} \mathrm{~h}$ $\mathrm{g}^{-1}$ by 100 th cycle, resulting in a very poor cycle performance. The significant capacity decay is attributed to a disintegration of Si electrode caused by a stress generated during alloying/dealloying reaction of $\mathrm{Si}$ with Li. Although the coulombic efficiency of the electrode in $\mathrm{PC}$ was temporarily increased to $99 \%$ at the 10 th cycle, the efficiency was decreased to $92 \%$ at the 33 th cycle. The decline results from the disintegration such as the peeling of the active material from the current collector. On the other hand, The Si electrode in PP1MEM-TFSA showed the first coulombic efficiency of $83 \%$, which is larger than that obtained from PP16-TFSA (68\%). These irreversible capacities come from the decomposition of electrolytes to form a surface layer on the anode. It was reported that surface layer derived from TFSA-based ionic liquids is composed of lithium fluoride $(\mathrm{LiF})$, lithium carbonate $\left(\mathrm{Li}_{2} \mathrm{CO}_{3}\right)$, lithium sulfate $\left(\mathrm{Li}_{2} \mathrm{SO}_{4}\right)$, and lithium sulfite $\left(\mathrm{Li}_{2} \mathrm{SO}_{3}\right){ }^{23}$ The Si electrodes in PP1MEM-TSFA and PP16-TFSA gave better cyclability: the capacities of over $1000 \mathrm{~mA} \mathrm{~h} \mathrm{~g}^{-1}$ were maintained even after 100th cycle. We were able to confirm the excellent reproducibility of anode performances in each case, and an advantage of utilization of ionic liquid electrolyte are obvious throughout the 100 cycles test (Figure 7). Although the capacity in PP1MEM-TFSA was higher than that in PP16-TFSA until 40th cycle, behaviors of cycle performances in each electrolytes overlapped after 50th cycle. From range of Li-insertion plateau between 0.005 and $0.120 \mathrm{~V} \mathrm{vs.} \mathrm{Li} / \mathrm{Li}^{+}$, the initial lithiation capacities based on $\mathrm{Li}-\mathrm{Si}$ alloying reaction in PP1MEM-TFSA and PP16-TFSA can be estimated to be about 2800 $\mathrm{mA} \mathrm{h} \mathrm{g}^{-1}$ and $2070 \mathrm{~mA} \mathrm{~h} \mathrm{~g}^{-1}$, respectively. These capacities are basically close to the theoretical capacity of $\mathrm{Li}_{13} \mathrm{Si}_{4}\left(3110 \mathrm{~mA} \mathrm{~h} \mathrm{~g}{ }^{-1}\right)$ and $\mathrm{Li}_{7} \mathrm{Si}_{3}\left(2230 \mathrm{~mA} \mathrm{~h} \mathrm{~g}^{-1}\right)$, and the volumetric change ratios per $\mathrm{Si}$ atom from $\mathrm{Si}$ to $\mathrm{Li}_{13} \mathrm{Si}_{4}$ and $\mathrm{Li}_{7} \mathrm{Si}_{3}$ correspond to $340 \%$ and $260 \% .{ }^{51}$

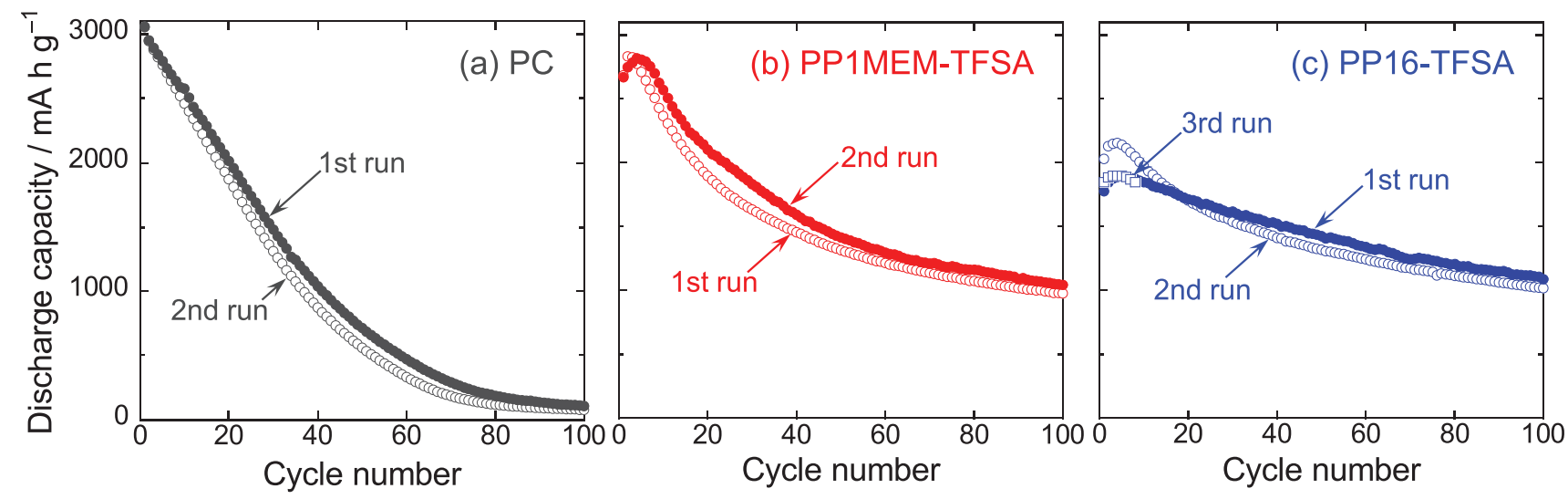

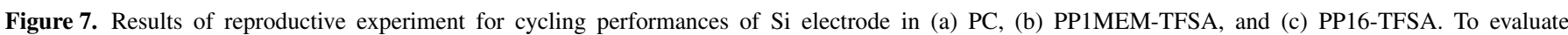
reproducibility, the performances were measured for another electrodes as 2 nd or 3 rd run sample. 


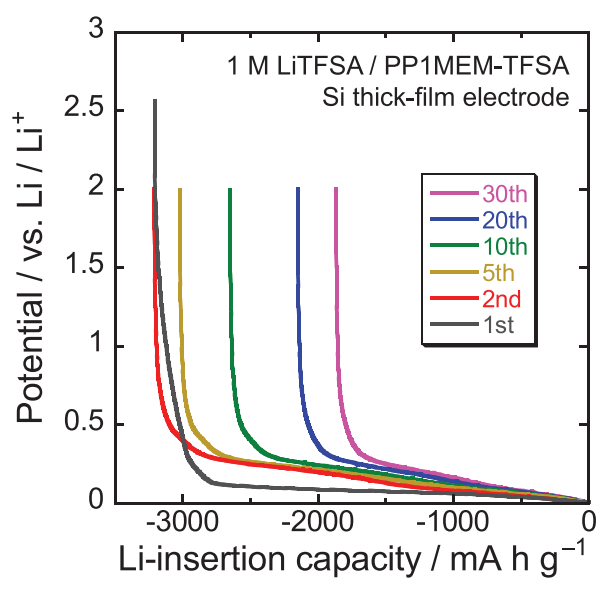

Figure 8. Charge (Li-insertion) profiles during the initial 30 cycles for $\mathrm{Si}$ thick-film electrode in PP1MEM-TFSA.

The Si in PP1MEM-TFSA expands by the difference in the volumetric change ratio, which results in a generation of a larger strain in the active material. In addition, we could not confirm an additional potential plateau or a shoulder related to the electrolyte decomposition with the exception of lithiation reaction from the charge profiles after second cycle (Figure 8). It is suggested that the lower efficiency in PP1MEM-TFSA is not relevant to the formation of surface layer such as solid electrolyte interphase (SEI). From the above, the reason for the capacity decay in the initial 40th cycle in PP1MEM-TFSA is considered to be due to the greater breakup of Si electrode. It was noteworthy that the Si electrode in PP1MEM-TFSA exhibited the initial capacity comparable to that in PC but still attained the high capacity of $1050 \mathrm{~mA} \mathrm{~h} \mathrm{~g}^{-1}$ at the 100th cycle. The essential difference in electrode performances obtained from the ionic liquid electrolyte and the organic electrolyte will be reported in future article.

Figure 9 displays FE-SEM images of the Si electrodes before and after 100th charge-discharge cycle in PC, PP1MEM-TFSA, and

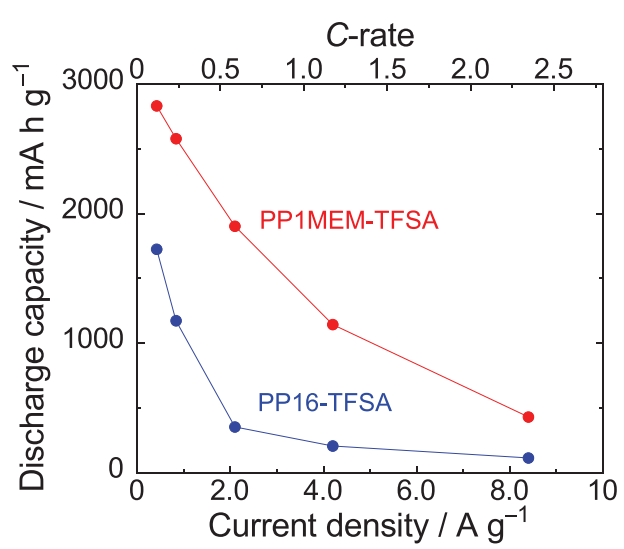

Figure 10. Rate capability of Si electrodes in PP1MEM-TFSA and PP16TFSA at various current rates from 0.42 to $8.4 \mathrm{~A} \mathrm{~g}^{-1}$.

PP16-TFSA. The as prepared Si electrode showed a comparatively smooth surface as shown in Figure 9a. After cycling in PC, we can clearly observe the disintegration of Si electrode related to the rapid capacity fading (Figure 9b). On the contrary, the disintegration of $\mathrm{Si}$ electrodes were relatively suppressed in the cases of using the ionic liquid electrolytes though there were changes in surface morphology such as partial breakup and the formation of cracks (see Figures 9c and 9d). Among them, the degree of disintegration of Si electrode in PP1MEM-TFSA was larger than that in PP16-TFSA, which also means that the capacity decay of Si electrode during the initial 40th cycle in PP1MEM-TFSA originates from the disintegration of the electrode.

Figure 10 illustrates a rate performance of $\mathrm{Si}$ electrodes in ionic liquid electrolytes. The characteristic of PP1MEM cation that reduces the interaction between Li ions and TFSA anions is expected to upgrade an anode performance of Si electrodes at high-rate charge-discharge condition. The rate capability was evaluated at various current densities from $420(0.12 C)$ to $8400 \mathrm{~mA} \mathrm{~g}^{-1}(1.2 \mathrm{C})$. The Si electrode in PP16-TFSA showed a rapid capacity decay with increasing current
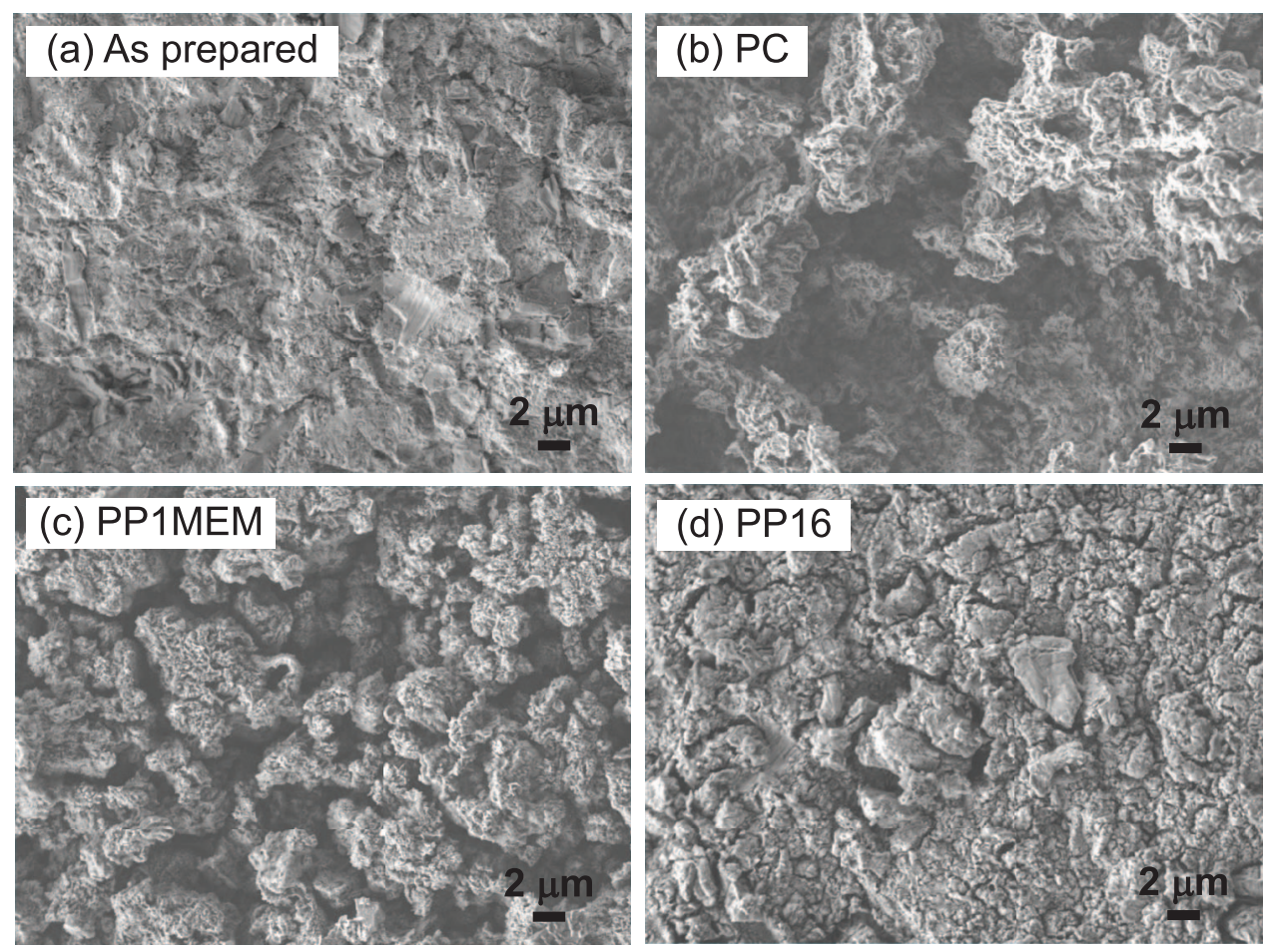

Figure 9. FE-SEM images of Si thick-film electrodes (a) as prepared and after 100th charge-discharge cycle in (b) PC, (c) PP1MEM-TFSA, and (d) PP16-TFSA. 
density: the capacity at $1.2 \mathrm{C}$ was $210 \mathrm{~mA} \mathrm{~h} \mathrm{~g}{ }^{-1}$, which corresponds to about one-tenth of the capacity at $0.12 C$. This poor rate capability results from slow kinetics of interfacial Li-ion transfer between the electrode and the electrolyte. On the other hand, PP1MEM-TFSA delivered a comparatively high discharge capacity of $1150 \mathrm{~mA} \mathrm{~h} \mathrm{~g}^{-1}$ even at a high current density of $4200 \mathrm{~mA} \mathrm{~g}^{-1}$ (1.2 C), indicating that the Li-ion transfer was remarkably improved by PP1MEM cation. An application of PP1MEM-TFSA to Si-based composite electrodes that we have demonstrated their superiority expects that the electrode performance can be further improved.

\section{Conclusions}

The Si thick-film electrodes were prepared by a gas-deposition method, and the influences of cation structure of ionic liquids on anode properties of $\mathrm{Si}$ electrodes were investigated from the viewpoint of interaction between $\mathrm{Li}$ ion and TFSA anions. The Si electrode in ionic liquid consisted of PP1MEM cation having electron-donating group and TFSA anion exhibited the high discharge capacity of $2670 \mathrm{~mA}$ $\mathrm{h} \mathrm{g}^{-1}$ at the first cycle, which is larger than that in PP16-TFSA by ca. $900 \mathrm{~mA} \mathrm{~h} \mathrm{~g}^{-1}$. Raman analysis and EIS measurements revealed that PP1MEM cation played a role reducing the interaction between $\mathrm{Li}$ ion and TFSA anions, and that Li-ion transfer at the interface between electrode and electrolyte was improved compared with PP16TFSA. The excellent cycle performances, discharge capacities of over $1000 \mathrm{~mA} \mathrm{~h} \mathrm{~g}^{-1}$ at 100th cycle, were attained in both the ionic liquid electrolytes whereas the Si electrode in PC showed the capacity of $110 \mathrm{~mA} \mathrm{~h} \mathrm{~g}^{-1}$. Additionally, the improved interfacial Li-ion transfer, the smooth Li-insertion into Si in PP1MEM-TFSA led to a good highrate performance: the capacity of $1150 \mathrm{~mA} \mathrm{~h} \mathrm{~g}^{-1}$ at relatively a high current density of $4200 \mathrm{~mA} \mathrm{~g}^{-1}(1.2 C)$ was achieved. These results indicates that the introduction of ether functional group into cation structure is effective strategy for enhancement of anode performance of Si electrodes.

\section{Acknowledgments}

M. Shimizu thanks Japan Society for the Promotion of Science (JSPS) for research fellowship (No. 2611485). This work has been supported by a grant-in-Aid for Young Scientists (B) (No. 25810141) from Scientific Research of Ministry of Education, Culture, Sports, Science and Technology (MEXT) of Japan. The authors thank A. Sato for synthesis of ionic liquids.

\section{References}

1. C. J. Wen and R. A. Huggins, J. Solid State Chem., 37, 271 (1981).

2. M. N. Obrovac and L. Christensen, Electrochem. Solid-State Lett., 7, A93 (2004).

3. T. D. Hatchard and J. R. Dahn, J. Electrochem. Soc., 151, A838 (2004).

4. M. N. Obrovac and L. J. Krause, J. Electrochem. Soc., 154, A103 (2007)

5. N. Ding, J. Xu, Y. X. Yao, G. Wegner, X. Fang, C. H. Chen, and I. Lieberwirth, Solid State Ionics, 180, 222 (2009).

6. J. Xie, N. Imanishi, T. Zhang, A. Hirano, Y. Takeda, and O. Yamamoto, Mater. Chem Phys., 120, 421 (2010).

7. M. Thakur, S. L. Sinsabaugh, M. J. Isaacson, M. S. Wong, and S. L. Biswal, Sci. Rep., 2, 795 (2012).

8. A. Magasinski, P. Dixon, B. Hertzberg, A. Kvit, J. Ayala, and G. Yushin, Nat. Mater. 9, 353 (2010)

9. Y. Chen, S. Zeng, J. Qian, Y. Wang, Y. Cao, H. Yang, and X. Ai, ACS Appl. Mater. Interfaces, 6, 3508 (2014).
10. C. Wang, H. Wu, Z. Chen, M. T. McDowell, Y. Cui, and Z. Bao, Nature Chem., 5, 1042 (2013)

11. H. Sakaguchi, T. Iida, M. Itoh, N. Shibamura, and T. Hirono, IOP Conf. Series: Mater. Sci. Eng., 1, 012030 (2009).

12. H. Usui, K. Meabara, K. Nakai, and H. Sakaguchi, Int. J. Electrochem. Sci., 6, 2246 (2011).

13. H. Usui, M. Shibata, K. Nakai, and H. Sakaguchi, J. Power Sources, 196, 2143 (2011).

14. H. Usui, N. Uchida, and H. Sakaguchi, Electrochemistry, 80, 737 (2012).

15. M. Ishikawa, T. Sugimoto, M. Kikuta, E. Ishiko, and M. Kono, J. Power Sources, 162, 658 (2006)

16. H. Sano, H. Sakaebe, and H. Matsumoto, J. Electrochem. Soc., 158, A316 (2011)

17. S. Seki, Y. Ohno, H. Miyashiro, Y. Kobayashi, A. Usami, Y. Mita, N. Terada, K. Hayamizu, S. Tsuzuki, and M. Watanabe, J. Electrochem. Soc., 155, A421 (2008).

18. M. Egashira, A. Kanetomo, N. Yoshimoto, and M. Morita, J. Power Sources, 196, 6419 (2011).

19. V. Baranchugov, E. Markevich, E. Pollak, G. Salitra, and D. Aurbach, Electrochem. Commun., 9, 796 (2007)

20. C. C. Nguyen and S.-W. Song, Electrochem. Commun., 12, 1593 (2010).

21. T. Sugimoto, Y. Atsumi, M. Kono, M. Kikuta, E. Ishiko, M. Yamagata, and M. Ishikawa, J. Power Sources, 195, 6153 (2010).

22. N. Yabuuchi, K. Shimomura, Y. Shimbe, T. Ozeki, J.-Y. Son, H. Oji, Y. Katayama, T. Miura, and S. Komaba, Adv. Energy Mater., 1, 759 (2011).

23. J.-W. Song, C. C. Nguyen, and S.-W. Song, RSC Adv., 2, 2003 (2012).

24. C. C. Nguyen, S.-W. Woo, and S.-W. Song, J. Phys. Chem. C, 116, 14764 (2012).

25. J.-A. Choi, D.-W. Kim, Y.-S. Bae, S.-W. Song, S.-H. Hong, and S.-M. Lee, Electrochim. Acta, 56, 9818 (2011).

26. H. Usui, Y. Yamamoto, K. Yoshiyama, T. Itoh, and H. Sakaguchi, J. Power Sources, 196, 3911 (2011)

27. H. Usui, T. Masuda, and H. Sakaguchi, Chem. Lett., 41, 521 (2012).

28. H. Usui, M. Shimizu, and H. Sakaguchi, J. Power Sources, 235, 29 (2013).

29. J. C. Lassegues, J. Grondin, and D. Talaga, Phys. Chem. Chem. Phys., 8, 5629 (2006).

30. Y. Umebayashi, T. Mitsugi, S. Fukuda, T. Fujimori, K. Fujii, R. Kanzaki, M. Takeuchi, and S. Ishiguro, J. Phys. Chem. B, 111, 13028 (2007)

31. Y. Umebayashi, S. Mori, K. Fujii, S. Tsuzuki, S. Seki, K. Hayamizu, and S. Ishiguro, J. Phys. Chem. B, 114, 6513 (2010).

32. M. Yamagata, N. Nishigaki, S. Nishishita, Y. Matsui, T. Sugimoto, M. Kikuta, T. Higashizaki, M. Kono, and M. Ishikawa, Electrochim. Acta, 110, 181 (2013).

33. Y. Katayama, R. Fukui, and T. Miura, J. Electrochem. Soc., 154, D534 (2007).

34. Y. Yamada, Y. Iriyama, T. Abe, and Z. Ogumi, J. Electrochem. Soc., 157, A26 (2010).

35. B. Baek, S. Lee, and C. Jung, Int. J. Electrochem. Sci., 6, 6220 (2011).

36. Y. Wang, K. Zaghib, A. Guerfi, F.F.C. Bazito, R.M. Torresi, and J.R. Dahn, Electrochimica Acta, 52, 6346 (2007).

37. H. Sakaguchi, T. Toda, Y. Nagao, and T. Esaka, Electrochem. Solid-State Lett., 10, J146 (2007)

38. M. Shimizu, H. Usui, and H. Sakaguchi, J. Power Sources, 248, 378 (2014).

39. Y. Abe, K. Yoshiyama, Y. Yagi, S. Hayase, M. Kawatsura, and T. Itoh, Green Chem., 12, 1976 (2010)

40. H.-B. Han, K. Liu, S.-W. Feng, S.-S. Zhou, W.-F. Feng, J. Nie, H. Li, X.-J. Huang, H. Matsumoto, M. Armand, and Z.-B. Zhou, Electrochim. Acta, 55, 7134 (2010).

41. J. Reiter, E. Paillard, L. Grande, M. Winter, and S. Passerini, Electrochim. Acta, 91, 101 (2013).

42. K. Tsunashima, A. Kawabata, M. Matsumiya, S. Kodama, R. Enomoto, M. Sugiya, and Y. Kunugi, Electrochem. Commun., 13, 178 (2011).

43. J.-T. Li, J. Swiatowska, A. Seyeux, L. Huang, V. Maurice, S.-G. Sun, and P. Marcus, J. Power Sources, 195, 8251 (2010).

44. I. Rey, P. Johansson, J. Lindgren, J. C. Lassègues, J. Grondin, and L. Servant, J. Phys. Chem. A, 102, 3249 (1998).

45. S. P. Gejji, C. H. Suresh, K. Babu, and S. R. Gadre, J. Phys. Chem. A, 103, 7474 (1999).

46. M. Herstedt, M. Smirnov, P. Johansson, M. Chami, J. Grondin, L. Servant, and J. C. Lassègues, J. Raman Spectrosc., 36, 762 (2005).

47. M. Kunze, S. Jeong, E. Paillard, M. Schönhoff, M. Winter, and S. Passerini, $A d v$ Energy Mater, 1, 274 (2011).

48. M. Kunze, E. Paillard, S. Jeong, G. B. Appetecchi, M. Schoenhoff, M. Winter, and S. Passerini, J. Phys. Chem. C, 115, 19431 (2011).

49. S. Tsuzuki, H. Tokuda, K. Hayamizu, and M. Watanabe, J. Phys. Chem. B, 109, $16474(2005)$

50. S. Tsuzuki, K. Hayamizu, S. Seki, Y. Ohno, Y. Kobayashi, and H. Miyashiro, J. Phys. Chem. B, 112, 9914 (2008).

51. M. K. Datta and P. N. Kumta, J. Power Sources, 194, 1043 (2009). 